\title{
An Ultra-Low-Cost Active Multispectral Crop Diagnostics Device
}

DOI:

10.1109/ICSENS.2017.8234211

\section{Document Version}

Final published version

Link to publication record in Manchester Research Explorer

\section{Citation for published version (APA):}

Veys, C., Davies, P., Hibbert, J., \& Grieve, B. (2017). An Ultra-Low-Cost Active Multispectral Crop Diagnostics Device. 1005-1007. Paper presented at IEEE Sensors 2017 Conference, Glasgow, United Kingdom.

https://doi.org/10.1109/ICSENS.2017.8234211

\section{Citing this paper}

Please note that where the full-text provided on Manchester Research Explorer is the Author Accepted Manuscript or Proof version this may differ from the final Published version. If citing, it is advised that you check and use the publisher's definitive version.

\section{General rights}

Copyright and moral rights for the publications made accessible in the Research Explorer are retained by the authors and/or other copyright owners and it is a condition of accessing publications that users recognise and abide by the legal requirements associated with these rights.

\section{Takedown policy}

If you believe that this document breaches copyright please refer to the University of Manchester's Takedown Procedures [http://man.ac.uk/04Y6Bo] or contact uml.scholarlycommunications@manchester.ac.uk providing relevant details, so we can investigate your claim.

\section{OPEN ACCESS}




\title{
An Ultra-Low-Cost Active
}

\section{Multispectral Crop Diagnostics Device}

\author{
Charles Veys $^{\dagger}$, James Hibbert ${ }^{\dagger}$, Phillip Davis ${ }^{\ddagger}$ and Bruce Grieve ${ }^{\dagger}$ \\ ${ }^{\dagger}$ School of Electrical \& Electronic Engineering, The University of Manchester, Manchester, United Kingdom \\ *Stockbridge Technology Centre, Cawood, Selby, UK \\ charles.veys@manchester.ac.uk
}

\begin{abstract}
A multispectral imaging system is presented, using components that will support its deployment within the world of small-holder agriculture. An active narrowband illumination setup was selected, which allowed a low-cost broadband image sensor to be used. The preliminary set-up has been demonstrated with droughted tomato plants as a proof of concept. The results demonstrated a 5, 28 and $90 \%$ deterioration after day 1, 2 and 3 respectively; calculated by the disease/water stress index. Initial analysis showed that for specific applications the device be used in lieu of high-cost diffraction gratings, however additional innovation is required to negate unwanted sensing phenomena.
\end{abstract}

Keywords-Agriculture, Crop Analysis, Multispectral Imaging, Remote Sensing, Drought

\section{INTRODUCTION}

Agrarian technology has developed significantly over the past decade, with the precision agriculture movement minimising superfluous operational and environmental costs. The application of spectral technology in-field has allowed for real-time monitoring and control of various stress factors. This growing understanding, of both biotic and abiotic stimuli, has allowed for increasing efficiency despite shifting climatic dynamics reducing the efficacy of traditional methods. Unfortunately, the potential benefit of this research is yet to be wholly realised within the industry, with the price-tag of cuttingedge technology leaving initial benefits to the larger conglomerates. As contemporary agricultural practices, reformed by innovative technology, evolve, the feasibility for small-scale farming returns and with it the requirement for relevant technology.

Spectral imaging creates multi-dimensional arrays of information which, due to the varying spectral interaction with plant tissue, can be interpreted to monitor the status of the plant. It has been applied to plant pathology as a powerful diagnostic tool to generate information-rich datasets, however, it is still a science very much under development; with much of the data texture yet to be fully interpreted and the volume of the data generated an additional barrier to implementation. Current industrial analytical devices include averaged point measurements and two-dimensional imaging, which link the literature on plant responses to optical cues. These have been applied positively, but lack reliability and depth of information due to their resolution and configuration. The most common form of spectral imaging is passive, where the reflected light is filtered, usually through a diffraction grating, which allows a small amount of light to pass onto an image sensor; this method is robust to ambient lighting, outside extremes, and allows for

This research was funded by an Eco-Innovation Voucher from the Higher Education Innovation Fund (HEIF) at the University of Manchester

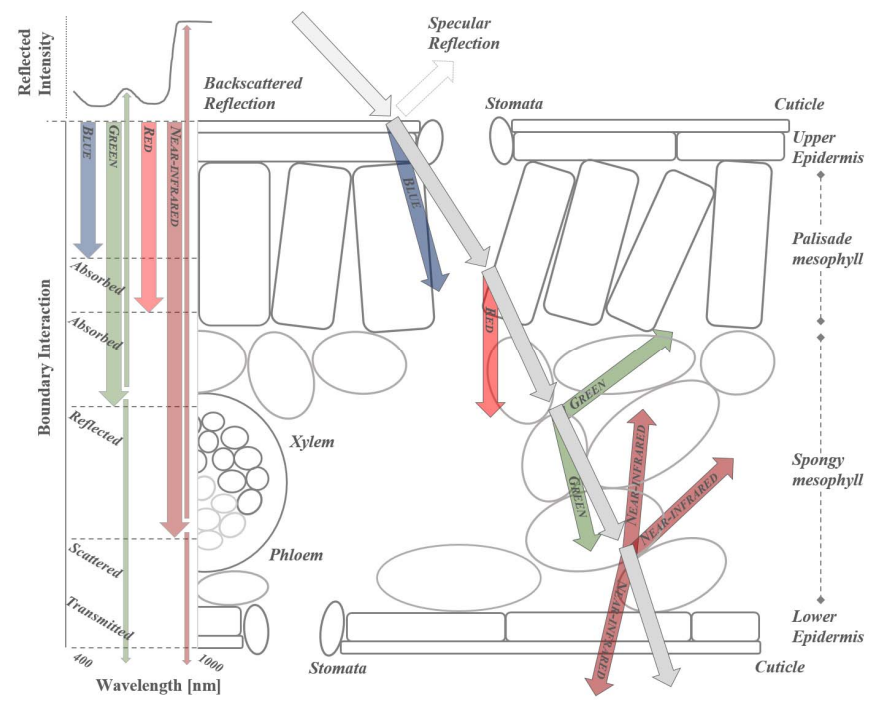

Fig. 1. Light spectra interaction with increasing penetration depth within leaf tissue, with backscatter reflection visualisation across the VIS-NIR range

very high spectral resolution over contiguous bands (hyperspectral). In active systems, the process is inverted, typically using a narrow band light source and a less sensitive detector but requires a controlled environment and results in a lower spectral resolution with discrete values (multispectral). Fortunately, the spectral information from crop samples, within the silicon response region, is smooth, as are most spectra containing structural information [1]. This means that a multispectral technique is sufficient for most crop diagnostics.

Plant tissue optics are complex due to the variability in both composition and orientation of the samples. Incident radiation comes into contact with the plant surface, where some reflects off the waxy cuticle in the form of specular reflectance, whilst the rest is refracted within the plant tissue, see Figure 1. It is the latter interaction that contains information about the internal sample composition. The dispersed light is either transmitted through the leaf, absorbed within the cell structure or reflected in the form of backscattered reflection. As the structure of leaf tissue is comprised of multiple layers, with varying composition, wavelengths penetrate to different depths [2] where light that reaches the spongy mesophyll is scattered. This explains plant tissue's apparent non-Lambertian reflectance, outlining why samples are often fixed in place before being imaged. This paper submits a prototype with features aimed at a specific application in order to negate previous shortfalls and capitalise on the availability of modern components. 


\section{MultisPectral Prototype Design}

This study investigated the application of a low-cost multispectral imaging system in a commercial indoor growing setting. The aim was to demonstrate the general technology readiness of such a low-cost system, whilst including information vital for crop performance and surveillance. This was achieved by (1) Demonstration of the prototype in a commercial growing environment; without specialised operation required. (2) Critical evaluation of the initial trial data; including the relevance of measurements. (3) Discussion of points of merit and shortfalls to inform a next generation setup.

\section{A. Component Breakdown}

The imaging system is designed to take advantage of the ever-reducing costs of consumer electronics. It has been produced in a modular fashion, so that the camera module and optics can easily be replaced to suit the specification; the imaging sensor currently used is the Sony IMX219, on an edited Pi NoIR v2 board in conjunction with the Raspberry Pi 3 embedded system. Light emitting diodes (LEDs) significantly reduce the amount of energy transferred to the sample over the full scan when compared to filament bulbs, and thus the temperature change of the sample. This narrow-band illumination method was demonstrated previously to improve the signal-to-noise ratio (SNR) on a passive system [3] and take advantage of higher spatial resolution cameras with a two band active system [4]. Our method uses an automated system with 35 active bands (full width half maximum (FWHM) of $\sim 10 \mathrm{~nm}$ ), evenly spaced within $400-980 \mathrm{~nm}$, able to create Spectral Vegetation Indices (SVIs) and forming a spectral reflectance plot for analysis. The illumination is driven from a custom printed circuit board (PCB) which, to maximise application in the field, permits the whole system to run off $12-24 \mathrm{~V}$ dc supply. The entire bill of materials of the imaging system comes in under $\$ 400$, without quantity reductions, and can be run from any laptop or mobile device with Wi-Fi capabilities.

\section{B. Mechanical Design}

There are a number of issues when attempting to image entire plant samples, or even canopies, which result from the heterogeneity within leaves and plant species. It has been known for some time that this illumination needs to be homogeneous, inside the field of view (FOV), so the LEDs used are collimated to $\sim 10^{\circ}$ before being back projected into an integrated hemisphere, see Figure 2, coated in a Barium Sulphate and white latex solution [5]. The housing was left open to allow access, thus the imaging took place in a dark environment (an indoor growing facility with controlled lighting); a shroud could be added for use outdoors.

\section{System Operation}

In order to maximise the SNR, the intensity of the narrowband sources and the exposure time of the acquisition are set using a barium sulphate reference object, due to its high uniform reflectance across the VIS-NIR. Once an object distance has been set, using a desired field of view, and the lens focussed manually, the automated system calibration is run. The values were chosen via an iterative approach, reducing the error step after each iteration, with a set-point intensity just below the saturation threshold of $90 \%$; as plant tissue does not reflect as much as the tile this procedure maximises the dynamic range of

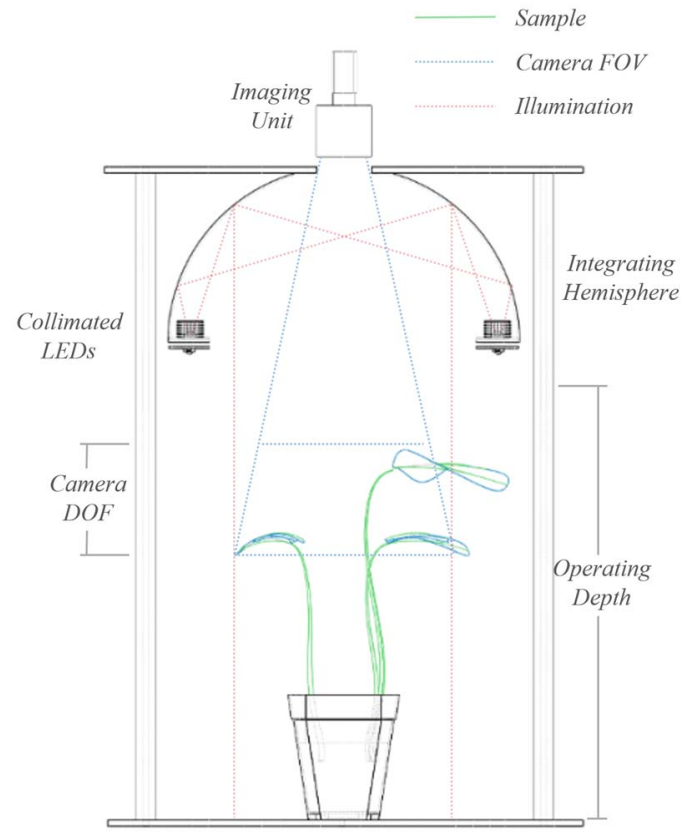

Fig. 2. Diagram of prototype showing method of diffuse illumination

the system, whilst preventing saturation. This operation meant that the data had to be normalised using this white tile set during pre-processing. This was achieved using an automated MATLAB (Mathworks Inc.) script, allowing the calibration to be repeated each time the set-up changes. During acquisition, a sample is placed in the centre of the housing with a spatial resolution setting of $0.1-0.5 \mathrm{~mm}$, with a corresponding scan routine of $180-30 \mathrm{~s}$ respectively. As the images are acquired through a Bayer filter, it is important to use a direct (1) and not weighted (2) intensity conversion, to prevent channels from being suppressed.

$$
\begin{aligned}
& \mathbf{I}=(\mathbf{R}+\mathbf{G}+\mathbf{B}) / 3 \\
& \mathbf{I}=(0.3 \times \mathbf{R}+0.6 \times \mathbf{G}+0.1 \times \mathbf{B}) / 3
\end{aligned}
$$

The background was removed using a Normalised Difference Vegetation Index (NDVI) threshold, before the image was normalised using a calibration tile matrix and the max intensity value for the spectra (3).

$$
\mathbf{I}(\lambda)=\mathbf{I}_{\mathrm{RAW}}(\lambda) \times \mathbf{C}(\lambda) \times \mathbf{I}_{\mathrm{MAX}}
$$

From here further SVIs were calculated, see Table 1, before the mean and standard deviation of each day plotted as a reflectance spectra.

TABLE I. Useful Spectral Vegetation Indices

\begin{tabular}{|l|l|l|}
\hline SVI & Full Name & Measurand \\
\hline NDVI [6] & Normalised difference vegetation index & Plant Tissue \\
\hline PSRI [7] & Plant senescence reflectance index & Senescence \\
\hline DWSI [8] & Disease/water stress index & Stress \\
\hline WI [9] & Water index & Water content \\
\hline TVI [10] & Triangular vegetation index & Pigment content \\
\hline
\end{tabular}




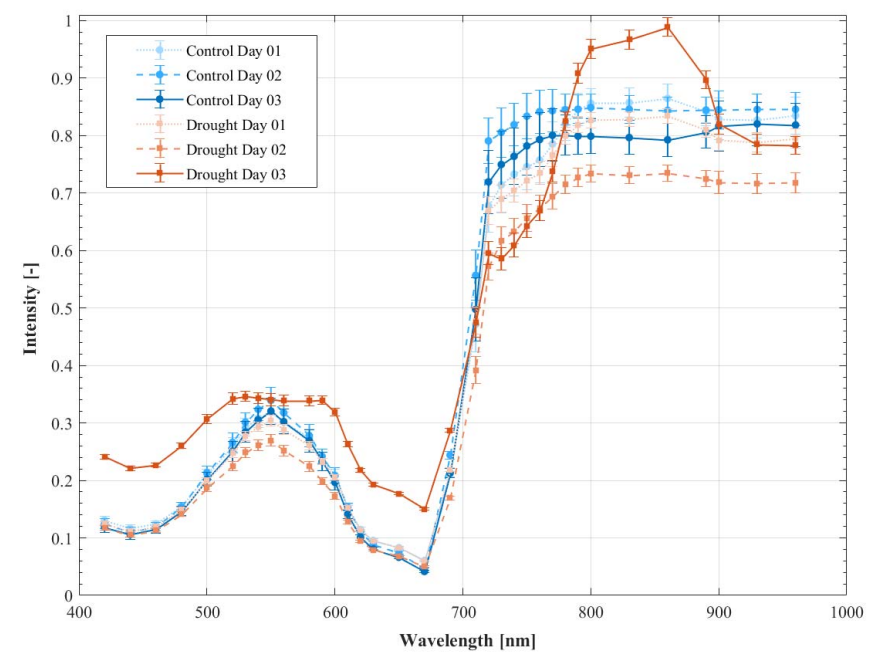

Fig. 3. Multispectral reflectance data of control versus droughted tomato plants over trial, error bars are equal to the standard deviation of whole plant

\section{EARLY RESULTS \& DISCUSSION}

The prototype system has been initially demonstrated using tomato (Solanum lycopersicum) plants, grown indoors under controlled conditions. The drought experiment was undertaken with six control plants and six plants that were not watered for three days with a scan taken apiece for each day. As you can see from Figure 3, the rate of senescence (spectra deformity) was small after the second day, however, the resultant change on the third in agreement with past literature of drought tissue degradation [11]. When comparing to the control plants there is a significant change when considering SVIs, even after only one day. It is well known that various SVIs have a strong correlation to their respective measurand, thus SVIs focused on plant stress and water content were selected, see Table 1. These metrics are often misleading and have little use in isolation; thus a percentage change from the control subset was calculated for each day and each SVI using (4).

$$
\Delta \operatorname{SVI}(\%)=100 \times\left(S V I_{D}(t)-S V I_{C T R L}(t)\right) / S V I_{C T R L}(t)
$$

In order to demonstrate this information clearly, a radar plot was used which displays the respective variation of each day for the selected SVIs, see Figure 4. This demonstrates the overall picture of reducing health over the trial, with increasing senescence whilst a reduction in water content.

Unfortunately, the rate of change of the crop sample reflectance, combined with the limited sampling rate, mean that further trials are required to effectively map out the trend of drought stress, and identify how early the process could be detected using such a system. There are a number of further points to be considered to improve the current set-up. It has become apparent that in order to image at the plant or canopy level, the reflectance measurements themselves do not tell the full story and in fact recording the structure of the sample is necessary [12]. Thus future designs will look at methods to record the surface orientation. The speed of acquisition currently limits high-throughput analysis and thus a more sensitive imaging unit is being considered.

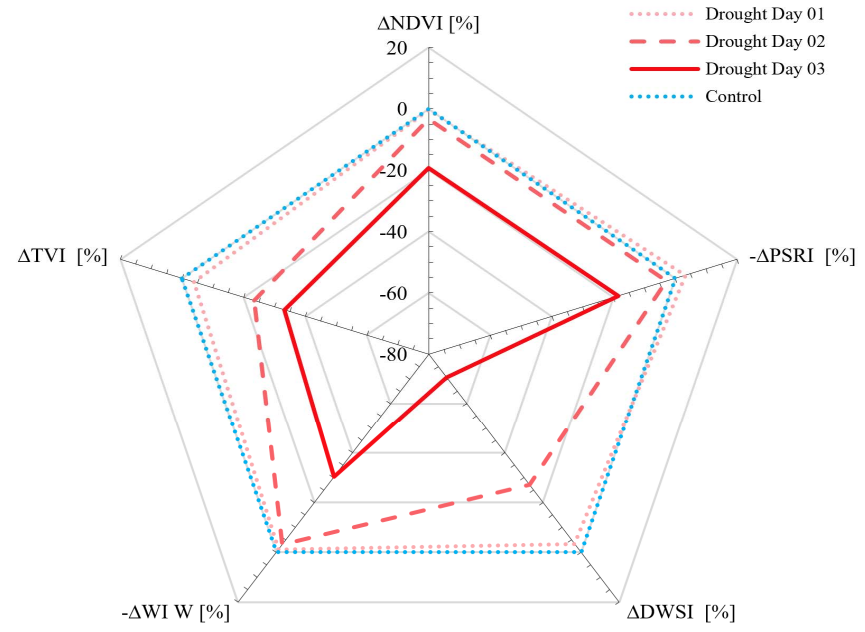

Fig. 4. Radar plot of showing percentage change of selected SVIs from the control for droughted tomato plants over a three day period

This equipment has opened the doors for applications of this method of sensing allowing for samples to be imaged in-situ, with accessible techniques and components. It is apparent that this low-cost spectral imaging device is a significant contribution to the world of crop research and agriculture.

\section{REFERENCES}

[1] H. Shen, L. Stordrange, R. Manne, O. M. Kvalheim, and Y. Liang, "The Morphological Score and its Application to Chemical Rank Determination," Chemom. Intell. Lab. Syst., vol. 51, no. 1, pp. 37-47, 2000.

[2] J. A. Abbott, "Quality measurement of fruits and vegetables," Postharvest Biol. Technol., vol. 15, no. 3, pp. 207-225, 1999.

[3] A.-K. Mahlein, S. Hammersley, E.-C. Oerke, H.-W. Dehne, H. Goldbach, and B. Grieve, "Supplemental Blue LED Lighting Array to Improve the Signal Quality in Hyperspectral Imaging of Plants," Sensors, vol. 15, no. 6, pp. 12834-12840, 2015.

[4] B. Grieve and S. Hammersley, "Localized Multispectral Crop Imaging Sensors," IEEE Instrum. Meas. Soc., p. 6, 2015.

[5] N. Knighton and B. Bugbee, "A Mixture of Barium Sulfate and White Paint is a Low-Cost Substitute Reflectance Standard for Spectralon," North, no. Figure 1, pp. 4-6, 1981.

[6] J. W. Rouse, R. H. Haas, J. A. Schell, and D. W. Deering, "Monitoring Vegetation Systems in the Great Okains with ERTS," Third Earth Resour. Technol. Satell. Symp., vol. 1, pp. 325-333, 1973.

[7] M. N. Merzlyak, A. a Gitelson, O. B. Chivkunova, and V. Y. U. Rakitin, "Non-destructive optical detection of pigment changes during leaf senescence and fruit ripening," Physiol. Plant., vol. 106, no. 1, pp. 135$141,1999$.

[8] a. Apan, a. Held, S. Phinn, and J. Markley, "Detecting sugarcane 'orange rust' disease using EO-1 Hyperion hyperspectral imagery," Int. J. Remote Sens., vol. 25, no. 2, pp. 489-498, 2004.

[9] J. Penuelas, J. Pinol, R. Ogaya, and I. Filella, "Estimation of plant water concentration by the reflectance Water Index," Int. J. Remote Sens., vol. 18, no. 13, pp. 2869-2875, 1997.

[10] N. H. Broge and E. Leblanc, "Comparing prediction power and stability of broadband and hyperspectral vegetation indices for estimation of green leaf area index and canopy chlorophyll density," Remote Sens. Environ., vol. 76, no. 2, pp. 156-172, 2001.

[11] J. Imanishi, Y. Morimoto, A. Imanishi, K. Sugimoto, and K. Isoda, "The independent detection of drought stress and leaf density using hyperspectral resolution data," Landsc. Ecol. Eng., vol. 3, no. 1, pp. 55-65, 2007.

[12] J. Behmann, A.-K. Mahlein, S. Paulus, H. Kuhlmann, E.-C. Oerke, and L. Plumer, "Generation and Application of Hyperspectral 3D Plant Models," Lect. Notes Comput. Sci., vol. 8928, pp. 117-130, 2015. 